\title{
O EU NA OBRA DE FREUD E A CORPORALIDADE¹
}

\author{
José Otávio de Vasconcellos Naves ${ }^{2}$ \\ Terezinha Féres-Carneiro ${ }^{3}$
}

Resumo: Este trabalho conjuga o conceito de eu na obra de Freud com o conceito de corporeidade em Merleau-Ponty, possibilitando um percurso teórico em que se pode pensar o corpo na sua perspectiva intersubjetiva. Na corporalidade, a "carne" de cada um, lançada ao mundo, se encontra na "carne" do outro, também lançada, para que re-efetue, na relação, uma troca expressiva inconsciente, a qual, porém, sem a consciência de um corpo subjetivado, perde suas possibilidades enquanto troca e expressão. $O$ recorte, em Freud, se inicia com os conceitos de eu prazer e eu da realidade, percorrendo a questão dos ideais em que se concretiza a possibilidade de pensar as relações do eu com o outro. Esses conceitos, paralelizados com a obra filosófica, trazem um suporte para a clínica psicanalítica.

Palavras-chave: Eu. Percepção. Consciência. Relação interpessoal. Corporeidade.

\section{Primeiras considerações}

O objetivo deste trabalho é fornecer uma perspectiva do conceito de eu em Freud, fazendo um paralelo com o conceito de corporalidade na obra de MerleauPonty. O eu foi conotado por Freud, no final de sua obra, sobretudo como uma "superfície corporal" (Freud, 1923/1996); mas o percurso aqui proposto não obedece a uma ordem cronológica. Serão valorizadas as diversas concepções encontradas na obra freudiana para enfatizar, principalmente, a formação do eu narcísico e seu lugar na segunda tópica para, por fim, reconsiderá-lo dentro de um contexto

1 Trabalho extraído de Tese de Doutorado do primeiro autor, realizada sob a orientação da segunda autora e defendida no Programa de Pós-graduação em Psicologia Clínica da Pontifícia Universidade Católica do Rio de Janeiro, em 2006.

2 Professor do Departamento de Psicologia da Pontifícia Universidade Católica do Rio de Janeiro. E-mail:jnaves@iis.com.br

3 Professora Titular do Departamento de Psicologia da Pontifícia Universidade Católica do Rio de Janeiro. E-mail: teferca@puc-rio.br

PSICOL. USP, São Paulo, jul./set. 2007, 18(3), 31-54 
mais próximo dos nossos propósitos, no âmbito de "Psicologia de Grupo e Análise do Ego" (Freud, 1921/1996).

Propomo-nos pensar esse conceito também na sua perspectiva intersubjetiva, isto é, como um intercâmbio de subjetividades em que, sem o corpo ou uma representação dele, a intersubjetividade não poderia existir.

Para construir esses objetivos buscamos o auxílio do pensamento de Merleau-Ponty (1964/2000). Consideramos enriquecedor esse paralelismo entre o pensamento fenomenológico e a psicanálise, sobretudo para se pensar o quadro mais grave de afecções que Freud denominou neuroses narcísicas. Essa denominação é encontrada em toda a sua obra depois de 1914, e pode ser entendida como uma possível nomeação da melancolia e da paranóia ou das formações clínicas que a psicanálise inglesa denominaria borderline. Esses quadros são expressão de uma intersubjetividade existente, mas difícil de ser manejada em seus aspectos transferenciais. Assim, procuramos justapor os conceitos de"corpo" e"eu" para, num futuro próximo, melhor compreendermos e considerarmos mais detidamente os subsídios que esta reflexão poderia fornecer para a solução de algumas das dificuldades encontradas no tratamento das afecções acima citadas.

\section{O eu e o sonho}

De início, no "Projeto para uma Psicologia Científica" (Freud, 1895/ 1996), a noção do eu se encontra bem próxima do campo da fisiologia. Evolutivamente concebida, ela se originaria de uma diferenciação no interior de uma espécie particular de neurônios, especialmente resistentes e detentores de capacidades diferentes das de outros neurônios: são mais permeáveis e menos obstinados na sua exigência de registro da experiência. Enriquecido sobretudo por um narcisismo original muito próximo da fisiologia e das formações mais primitivas do corpo do bebê, esse eu atuaria, desde o início, como uma função defensiva, avaliando e reconsiderando as estimulações de uma maneira particular, e impedindo, dessa forma, o aparelho psíquico de vivenciar uma quantidade insuportável de estimulação.

Antes, desde o artigo denominado "As Neuropsicoses de Defesa" (Freud, 1894/1996), o eu já era pensado como uma força defensiva diante da representação inconciliável. Naquele texto se encontravam mais ou menos esboçados dois processos que seriam burilados mais tarde, em 1900, em "A Interpretação dos Sonhos". O primeiro, denominado"primário", se inicia com o trabalho da pulsão como movimento de descarga da tensão, em que a autodefesa se expressaria por excelência, tornando-se o apoio futuro para a pulsão sexual. As defesas primárias se 
apresentam como "realizações alucinadas de desejo", processo quantitativo que se afiguraria como uma cota insuportável de estímulo que demanda resposta. $O$ exemplo mais conhecido seria a alucinação do seio como defesa primitiva. Não obstante esse mecanismo, porém, o trabalho não terminaria aí. A excitação que foi retirada, porque insuportável, deve ser reconduzida a uma outra utilização, já que, por princípio, essa energia está lá e não pode ser subtraída. Conseqüentemente, deve ser levada a percorrer novos caminhos.

Mas essa compulsividade das defesas primárias leva Freud a pensar a construção de uma nova economia, denominada "processo secundário", que se estabeleceria através do reconhecimento das diferenças, possibilitando retardamentos e defesas secundárias. Essas diferenças seriam, primordialmente, definidas e consideradas em referência a uma quota positiva ou negativa de energia. Mesmo que ainda não amplamente qualificadas, através do "a mais" ou "a menos" de suas próprias estimulações, elas estabeleceriam e sustentariam um primitivo processo de diferença quantitativa - mas diferença, de qualquer modo.

Assim, o primeiro processo se estabeleceria unicamente como descarga de tensão, e o segundo, mesmo buscando essa descarga, se deixaria pautar pela diferença. Mas ambos teriam o seu ponto de partida no elemento pulsional; logo, numa representação corporal que seria denominada, mais tarde, como a fonte da pulsão (Freud, 1915a/1996).

E qual seria o destino desses afetos? No rascunho $\mathrm{H}$, intitulado "A Paranóia", anexo à carta a Fliess de 24 de janeiro de 1895, Freud (1895a/ 1996) fará um esboço inicial dessas "defesas secundárias", isto é, tentará elaborar o destino do afeto retirado da antiga representação insuportável. Na histeria, o afeto intolerável seria, daí em diante, deslocado e recolocado no corpo somático pela conversão. Nas idéias obsessivas, e a duras penas, o afeto também seria mantido fora das representações do eu, não encontrando, todavia, saídas melhores do que um certo ritualismo que o encerraria dentro dessa dominação mais ou menos garantida.

$\mathrm{Na}$ alucinação, entretanto, o conjunto formado pela representação e pelo afeto é mantido afastado, e o preço a pagar seria um afastamento parcial do mundo exterior. Nesse caso, o exemplo seria a paranóia. Nela, representação e afeto são contidos pelo eu que, entretanto, os projeta no mundo exterior. Ao contrário das primeiras, acima citadas, essas anotações já podem ser consideradas manifestações clínicas por excelência, isto é, observáveis através da relação transferencial estabelecida pelo cliente. E pertinentes, assim, aos objetivos deste artigo.

O rascunho N (Freud, 1897/1996), anexo a uma carta a Fliess de 31 de maio de 1897, sugere uma concepção do eu que, na sua função defensiva, pode se confundir com o pré-consciente. Seria o primeiro momento, dentro da primeira tópica, em que o eu poderia talvez ser compreendido como um lugar do aparelho, e não unicamente como uma 
defesa, possibilitando continuidade e preservação ao construído, como será considerado na segunda tópica.

A libido, como uma primeira força motivadora, reapresentada aqui como complexa estrutura de pulsões e fantasias, encontraria o eu situado como uma fronteira entre ela e o mundo externo. Essa noção de reservatório mediador situa o eu entre o mundo e o desejo, e, logo, próximo da questão corporal, já antevendo as considerações que viriam a ser mais elaboradas no artigo "O Eu e o Id" (Freud, 1923/1996).

Continuando nossa pesquisa pelo texto freudiano, pode-se dizer que na primeira edição de "A Interpretação dos Sonhos" (Freud, 1900/1996) não se encontra nenhuma referência mais explícita ao eu. Será nas edições de 1911 e 1914 que, gradualmente, essas referências vão surgir.

Desde o texto de 1900, porém, já se pode pensá-lo como um agrupamento de identificações, mesmo que o conceito de identificação esteja apenas sugerido. Os mecanismos de condensação e deslocamento, no referido texto, não mais permitem que se deixe de associá-los à identificação, seja em função das figuras do sonho, seja pelo próprio discurso de quem o narra. As figuras do sonho são representações do eu do sonhador. Assim, pedaços ou traços dele se apresentam deslocados para cada representação.Todos esses pedaços seriam representações do eu nas suas inúmeras facetas; logo, identificações.

O sonho, nessa relação com o eu, é também uma defesa, uma forma expressiva da representação do conflito, considerada, em princípio, impossível. Por que impossível? Porque posicionada muito perto do umbigo do sonho, lugar mítico de formação do inconsciente, foco do narcisismo primordial e das primeiras transformações que construiriam, da carne do bebê, uma realidade psíquica.

Entretanto, é possível pensar a função do eu onírico também na sua relação com o sono, não somente como uma defesa, mas sim como o seu avesso. Explicando melhor: agora, o sonho também promove o sono e, assim, defende o sonhador da eventualidade do acordar. É nessa perspectiva que ele favoreceria a descarga libidinal. Sua função, guardando e promovendo o sono, é inovadora: aos seus cuidados, a pulsão continua o seu caminho, cabendo ao eu defendê-la das estimulações exteriores que possam impedir as suas expressões. $O$ discurso do sonho reformula o estímulo perceptivo, diminuindo seu valor e seu apelo; e, ao reintegrá-lo à situação desejada, favorece a expressão do desejo.

As condições formadoras do sonho, os restos diurnos, mais ou menos importantes, são, também, excitações do mundo e da biologia. $O$ eu se obriga a relançá-las no sonho, reconstituindo-as pela via do desejo. Assim, é interessante enfatizar que as excitações externas são de toda ordem e que o eu se constitui através de uma estimulação perceptiva desse tipo - pois, teoricamente, para o bebê, a primeira estimulação é uma estimulação do mundo, quantitativa, que o acorda como corpo psíquico. 
Sendo ele, inicialmente, uma carne biológica, inicia-se imediatamente seu processo de transmutação em uma realidade psíquica que, no entanto, não abdica de sua fonte corporal.

Assim, o conceito de eu, até esse momento, passeia entre um mecanismo defensivo da integridade psíquica fustigada pelo desejo e, por outro lado, um mecanismo propiciador que fornece o esboço de um espaço, mesmo que ao preço de uma mobilidade não muito favorável ao seu "suposto poder", mas que permite certa continuidade à realidade psíquica. De todas as formas, o sonho promove uma enorme descarga de desejos proibidos que são, na verdade, a síntese da alma infantil, no seu caminho para uma intersubjetividade adulta.

Sua função de defesa será atenuada, especialmente após a teoria do narcisismo. Mas em "Inibições, Sintomas e Ansiedade" (Freud, 1926/ 1996), posterior ao trabalho sobre o narcisismo, o estudo da inibição colocada por Freud, em seus exemplos, muito perto do corpo - lembra, de uma forma mais clínica e menos fisiológica, os neurônios que haviam sido sua referência no "Projeto para uma Psicologia Científica" (Freud, 1895b/1996). Freud retoma, assim, suas antigas concepções de defesa colocando, porém, o recalque nessa mesma categoria.

Nesse contexto, Freud levanta a possibilidade de que, antes da diferenciação entre o isso e o eu, e antes do aparecimento do supereu, o aparelho psíquico pode, quando estados primitivos são atingidos, utilizar processos de defesa diferentes daqueles já melhor estudados. Esta é uma hipótese freudiana que analistas como Klein e Winnicott, trabalhando em solo inglês, vieram a examinar. Hipóteses como essa, a nosso ver, são importantes para se pensar a expressão de uma superfície corporal que o eu iria, cada vez mais, representar na obra freudiana. Essa superfície corporal pode ser pensada não como uma aparelhagem psíquica brotando no mundo, simplesmente, através de suas estimulações traumáticas, mas como um intercâmbio entre o mundo e o bebê.

\section{O eu prazer e o eu realidade}

Até este ponto, falando dessas posições do eu, não foi dada ao egoísmo da criança a ênfase necessária. Ela é tomada por seus desejos e pela sua luta para satisfazê-los. É uma luta pelo que ela considera "seu bem", sem maiores valorações. É verdade, por outro lado, que a realidade não é assim tão simples, pois desde os primeiros momentos a criança busca civilizar-se, procurando alguns deveres altruístas e mais ligados a uma vida moral. Seria de se pensar, portanto, que um eu secundário tenta continuamente recobrir esse eu primitivo egoísta, altamente valorado em sua busca de satisfação. 
Pode ser considerado narcísico o eu egoísta que está voltado para o prazer e que é, inclusive, capaz de satisfazer-se auto-eroticamente. Mas pode-se, além disso, opor ao pólo do prazer narcísico o pólo de um desenvolvimento também egóico, porém nomeado como "eu da realidade", que tenderia a se curvar às exigências do mundo. Esse pólo teria como função principal uma distinção entre o fora e o dentro. De início, o interior será formado pelo que é bom (as estimulações prazerosas, constantes e suportáveis), e o exterior será formado por aquilo que é árduo (nãoprodutor de sentido imediato). Logo, esse exterior ficaria associado ao mal-estar.

É verdade que, segundo o artigo"Formulações sobre os Dois Princípios do Funcionamento Mental" (Freud, 1911/1996), a primeira fase (originária e auto-erótica) seria vivida durante os momentos mais primitivos do bebê.Trata-se do narcísico original, através do qual o eu, investido pelas pulsões, se encontra capaz de satisfazer, por si mesmo, suas expressões de desejo. Assim pensado, o eu coincidiria aqui com o que é prazeroso, mas o mundo exterior ainda seria considerado indiferente. Assim, o mundo exterior não participaria desses primeiros momentos, e não se apresentaria como uma possibilidade de intercâmbio. Esse momento, entretanto, é considerado teórico, ou seja, uma construção necessária e pouco clara na clínica, apesar de concebível como hipótese construtiva de uma importante defesa esquizóide.

Na perspectiva freudiana, somente numa segunda fase o eu já estaria recebendo experiências do mundo. Experiências de objeto, como o seio, pois as pulsões de autoconservação e as relações com o mundo assim o exigem. Mas, ao mesmo tempo, ele já não pode evitar a experiência de excitações pulsionais internas, que já seriam consideradas, mesmo temporariamente, como desagradáveis. Assim, esse "eu prazer" afasta de si mesmo partes que anteriormente o integraram, e as lança ao mundo. Teríamos, então, recobrindo-se, duas importantes novas polaridades do eu que tomariam lugar, em sua tentativa concomitante de realização de desejo, civilização e submissão ao teste da realidade. Essas polaridades seriam o eu e o mundo exterior (anterior indiferença) agora desprazeroso. $O$ eu, assim estabelecido, coloca a busca de realização de desejo acima de qualquer outra e sente o mundo exterior como hostil, já que constituído por aquilo que, em si mesmo, um dia havia sido considerado fonte de desprazer.

Melanie Klein (1951/1991) é quem dará maior ênfase a esse eu, pensando-o como uma contradição viva de ódios e amores. No entanto, tais observações são encontradas mais tarde na obra freudiana, agora 
conotadas como"masoquismo primário",em associação à pulsão de morte. Na relação de transferência, ele se mostraria sob a forma de um "sadismo avassalador".

A partir daí, não mais se trataria de saber se o que foi integrado ou lançado fora é bom ou mau, mas se o que está integrado ao eu egoísta como uma representação pode ser também redescoberto na realidade do mundo. Esse intercâmbio não é novo, e talvez estivesse constantemente relançado na obra de Freud sob diversas formas. $O$ jogo da projeção e da introjeção pode levar a pensar que, desde o início, algum descobrimento já teria sido elaborado para que a procura de objeto pudesse ter o seu lugar, pois o objetivo primeiro do teste da realidade não é somente encontrar um objeto no mundo, mas reencontrá-lo; e não apenas na realidade da percepção que lhe dá apoio, mas também na qualidade gerada pelo "eu prazer" que lhe dedicou valor específico como experiência afetiva e pessoal.

A semente do eu é perceptiva, pois vem de uma estimulação do mundo; mas todo acesso ao mundo é possível pelo teste da realidade, nos seus julgamentos de existência e qualidade, mesmo quantitativos. Acreditamos que essa semente perceptiva do eu nunca foi abandonada na obra freudiana, assim como esse intercâmbio com o mundo pode ser pensado como inicial, mesmo se precário quando a intersubjetividade por ele produzida não produz um lugar de sucesso.

Essas considerações se confirmam em 1925. No artigo "A Negativa" (Freud, 1925/1996), traz novas concepções a respeito desse "eu egoísta e faminto" em suas relações com o princípio da realidade, considerando-o definitivo, mesmo que marcado e aparentemente modificado por experiências posteriores. Freud pontua, nesse artigo, que para entender esse passo à frente é preciso não se esquecer de que todas as representações internas se originam de percepções. Essa característica da percepção marca o bebê tanto como emitente de sinais ao mundo, como de receptor das estimulações que emanam dele.

"A Negativa", entretanto, coloca a questão do eu como aglomerado de traços verbais. Esse texto diferencia as representações do inconsciente, recolocando as palavras no lugar que lhes será para sempre reservado: o de representações prioritárias do sistema "pré-consciente". Não é possível esquecer que tal texto é fundamentado numa estrutura de linguagem, descrita por Freud através da seguinte negativa:"não é minha mãe!". Essa negativa é uma expressão do recalcado, já abalado, mas ainda hesitante nas suas aproximações com o teste da realidade.

A função de julgamento e elaboração ofereceria, também, uma contribuição ao que é subjetivo e ao que é objetivo. A reprodução de uma percepção em representação pode ser alterada pela fusão de vários elementos, ou modificada por omissões. $\mathrm{O}$ eu se proporia a enviar peque- 
nas quantidades de energia com a finalidade de verificar, pela identidade de pensamento, a qualidade do objeto percebido. Mais tarde, em"Além do Princípio de Prazer" (Freud, 1920/1996) e em "Uma Nota sobre o'Bloco Mágico'" (Freud, 1925a/1996), Freud repensaria essa passagem e admitiria que o inconsciente é que estenderia sensores, através do sistema pcptcs, em direção ao mundo externo.

Seria um movimento de ir e vir não sucessivo, mas concomitante, sem espaço algum, como as palavras antitéticas, que contêm duas idéias contraditórias. $\mathrm{O}$ eu teria, como semente, na sua existência primeira, esse aspecto antitético. $O$ julgamento de uma qualidade boa ou má seria posterior. O antitético já lá estaria, imantado inicialmente pelas suas emanações de angústia, como uma semente primitiva de si mesmo, de sua subjetividade e de suas relações com as estimulações produzidas pelo mundo e pelas outras subjetividades.

Assim, continua Freud no artigo sobre a negativa, o desejo geral de negar, o negativismo psicótico, poderia ser encarado como sinal de uma desfusão das pulsões, efetuada através dos componentes libidinais. Essa expressão primitiva do eu é interessante para ser pensada como referência também nas neuroses narcísicas (e não unicamente nas psicoses), e poderia ilustrar o núcleo primordial tanto da reação terapêutica negativa quanto da ambivalência. Contudo, dentro das intenções deste artigo, esse antitético pode fornecer, numa futura pesquisa sobre a corporeidade do eu, um excelente pano de fundo para um trabalho clínico, pois é exatamente dele que o objeto surgirá.

\section{O eu e os ideais}

O artigo sobre o narcisismo (Freud, 1914/1996) traz considerações extremamente importantes para a teoria do eu. A sexualidade, ora investida no eu, ora no objeto, e dentro do modelo hidráulico, é uma exploração absolutamente nova. Na escolha narcísica, os objetos são reflexos, espelhos de objetos internos que o eu ama "como a si mesmo" ou "à sua maneira".

Essa teoria dá ensejo, como se verá adiante, a uma análise mais consistente da patologia do psiquismo individual; e, ao mesmo tempo, permite compreender o modo de introdução de cada psiquismo no contexto psicossocial, onde terá condições de civilizar-se e integrar-se. Essa possibilidade é fruto da "nova ação psíquica", como um momentoso processo que constitui a unificação narcísica.

O "eu ideal" (Idealich) seria esse universo libidinal primitivo através do qual o eu se forma. O infantil (egoísta e narcísico) se encontra dono de todas as satisfações e tem o controle onipotente de seus objetos. Mais tarde, o eu procurará estabelecer condições sociais a fim de que possa, 
refazendo-se, situar-se dentro de um "mundo" que lhe permita satisfazerse dos prazeres que um dia ele acreditara ter-se fornecido. Assim, o desejo se inclui numa realidade externa onde encontra simulacros daqueles objetos nunca tidos, considerados como perdidos e sempre desejados. Nessa travessia do mundo revestido pelo auto-erótico para o hetero-erótico, a teoria do narcisismo descreve um processo no qual "cada ser" se forma como "cada ser"e, ao mesmo tempo, se inclui no "humano" que é o "seu mundo".

O estudo a respeito do narcisismo (Freud, 1914/1996) permite a Freud considerar a libido, quando desinvestida da meta (Ziel) sexual, como uma forma de conhecimento, transformando o cognoscível do mundo em algo egóico. Isto se dá porque é através dos investimentos da pulsão, antes claramente sexualizados, que o ser humano não só conhece o mundo mas, também, descobre-se como corpo no mundo. A pulsão transforma o que era uma "mera possibilidade cognoscível" numa experiência vivida, chamada conhecimento de si e do outro, ou seja, algo particularmente matizado pelas experiências de cada ser, que poderíamos denominar, pelo seu contínuo intercâmbio com o outro, como uma intersubjetividade. E essa experiência, assim vivida, vai subjetivar também o corpo biológico, tornando-o suporte de uma aparelhagem psíquica apta aos embates do desejo.

A noção de organismo psíquico, então, pode atravessar a idéia de corpo físico, já que o narcisismo, para Freud, é também uma forma de conhecimento desse organismo: não só de seu contorno, mas também do próprio interior dele. Entre outras coisas, a realidade psíquica abrange, por exemplo, os movimentos musculares, intencionais ou não. Assim, ela inclui a possibilidade de planejar um movimento ou recriar a cena de movimento, seja internamente (como intenção projetada no mundo ou trazida para o eu mesmo), seja externamente, tal como o movimento do bailarino, que ultrapassa as fronteiras do corpo físico para expressar uma "alma" que habitaria essa mesma fronteira.

Ainda no artigo sobre o narcisismo (Freud, 1914/1996), tentando explicar a hipocondria, Freud escreverá que as experiências do interior do organismo serão progressivamente libidinizadas. Se elas se iniciam, teoricamente, no orifício bucal do bebê, quando uma borda se instala como fruto de suas primeiras experiências, da mesma forma, será importante para o bebê a experiência que terá, por exemplo, de seu coração como órgão interno. Essa experiência lhe será fornecida por uma série contínua de libidinizações, estimuladas pelos batimentos tanto de seu próprio coração quanto do coração de um outro organismo semelhante ao dele. Mas esse mesmo coração também ganha uma série de significações que lhe são atribuídas através da linguagem: por exemplo, como sede da experiência amorosa, sentimental. 
Pode-se dizer que a partir de 1914, época em que foi escrito "Sobre o Narcisismo: uma Introdução" (Freud, 1914/1996), o eu, em Freud, passa a ter uma enorme abrangência, ainda mais ampliada por ser esse eu a única possibilidade de acesso ao mundo.

\section{O eu e o outro}

Uma horda primária seria responsável pelas primeiras ligações de cada humano com o humano - não só com o social desse humano mas, também, com o humano de si mesmo. Cada psiquismo, por si só e em sua angústia tornada única, se orientaria, então, não apenas por uma ética monopolizada pelo linguajar comum, mas também por uma ética pessoalizada a partir daquela constituição do humano. Por isso, unidas, a criatividade e a ilusão fazem com que a realidade psíquica se refira a outras figuras intermediárias (objetos transicionais, como diria Winnicott, 1951/2000) suportadas, certamente, por sombras de cavernas semelhantes às dos homens primitivos, de "Totem e Tabu" (Freud, 1912-1913/1996), fantasmas que são, ao mesmo tempo, molambos de lençóis infantis triturados e lambidos por crianças. Tais sombras aproximam-se das antigas alucinações do objeto do desejo, agora mais bem definidas em seus contornos através dos objetos intermediários. Assim, além do pai que valida e torna possível uma certa singularidade na passagem pelas coisas, Freud mostra que, em cada ser humano, existiria um traço que sempre estará presente. Nesse momento, o eu surge do isso, acima descrito pela própria distinção entre o instinto e a pulsão que o traço primário provoca.

Em “O Ego e o Id" (Freud, 1923/1996), propõe que, embora se organize em torno do sistema "pcpt-cs", o eu não abandonaria essa característica, pois toma do isso os coloridos inconscientes que também o podem caracterizar. Porém, no decorrer da obra freudiana, o eu se tornaria um conjunto relativamente organizado de experiências a partir dos contatos com o mundo externo, sobretudo se levarmos em consideração a horda do Pai primevo, acima trabalhada. Em outras palavras, o eu sofre constantes modificações a partir de todas as experiências, tanto na sua ontogênese quanto na sua filogênese. Desde a"nova ação psíquica",aquela que constitui o narcisismo unificador, já organizado, a energia do eu é a libido pulsional. Mas agora Freud estende essa observação a todos os organismos que um dia participaram de sua filogênese. Diz ele:"A diferenciação entre o eu e o isso deve ser atribuída não apenas ao homem primitivo, mas até mesmo a organismos muito simples, pois ela é a expressão inevitável da influência do mundo externo" (Freud, 1923/1996, 
p. 50). Essa assertiva é interessante e reconfirma algumas considerações anteriormente esboçadas neste trabalho.

Neste ponto, o exemplo do cavalo e do cavaleiro se torna esclarecedor. Na segunda tópica, é o eu que torna possível a relação do isso com o mundo - é o eu que o agencia pela motricidade que buscaria no mundo os objetos desejados. Assim, em suas relações com o isso, o eu se comportaria como o cavaleiro que, aparentemente, domina as forças maiores do cavalo, levando-o pelos caminhos já estabelecidos. Entretanto, não se pode esquecer que a energia do eu é, originalmente, energia do isso que o eu empresta do contexto narcísico no qual se instala. Isto quer dizer que o eu nunca pode se separar, inteiramente, de sua necessária dependência energética do isso. Assim, ele se comporta como um cavaleiro que permite ao cavalo a condução, mascarando-se de um poder que na verdade não tem. De qualquer modo, será sempre dentro desse coletivo, no qual o laço social foi instalado, que o eu passeará como se cavaleiro fosse - mas seria no mais profundo de cada um que ele estaria primordialmente confundido com o movimento pulsional egoísta e ambivalente já trabalhado anteriormente. O "eu prazer", resistindo aos embates da experiência, estaria mais próximo do isso e talvez tenha sido, por um tempo, a única expressão possível do isso, mesmo que aos poucos vá cedendo e comece a ser colorido pelos impulsos narcísicos e idealizados, que o emergente "eu da realidade" Ihe impõe. Até que esse processo se desenvolva plenamente, uma ambigüidade estrita se manteria em seu cerne.

Entretanto, a progressiva separação do eu a partir do isso não é simples e passa, fundamentalmente, tanto pelo corpo como pela percepção. Citando Freud (1923/1996):

O eu é, primeiro e acima de tudo um eu corporal, não é uma entidade de superfície, mas é, o próprio eu, a projeção de uma superfície. Se quisermos encontrar uma analogia anatômica para ele, poderemos identificá-lo melhor com o homúnculo cortical dos anatomistas, que fica de cabeça para baixo no córtex, estira os calcanhares, tem o rosto virado para trás e, como sabemos, possui sua área de fala no lado esquerdo. (p. 39)

O eu consciente deve ser capaz de se deslocar dessa superfície corporal (uma pele corporal supostamente receptora e uma massa muscular emissora em suas continuidades com o mundo). Como um preço pago por ele mesmo, algo se separa do próprio corpo para se tornar o eu das representações (inicialmente inconsciente), ao mesmo tempo em que se diferencia do isso como reservatório das pulsões. Algo se separa das percepções, agora transformadas em representações e afetos, e as transforma num outro organismo, que Freud denominou psíquico, ou seja, intersubjetivo e enriquecedor das suas possibilidades corporais através de sua capacidade de inserção na linguagem. 


\section{A carne do bebê e a carne do mundo}

Elaboramos o percurso do conceito de eu em suas relações com o mundo na obra de Freud. Aqui se entende como mundo o "outro", em todos os seus aspectos, desde o seio que alimenta até as relações culturais (das mais usuais às mais inusitadas), englobando, também, todos os conteúdos civilizatórios que a humanidade criou para se afastar de sua animalidade anterior. Até agora, foram comentadas as defesas que o eu faz de seu mundo interno e as relações que estabelece com o mundo externo. Merleau-Ponty (1964/2000), em seus estudos sobre a experiência intersubjetiva, oferece um suporte para o trabalho que aqui apresentamos.

Para o autor, a percepção pode ser pensada como campo específico em que o percebido não está deformado por nada. Correlacionando essa afirmativa à noção freudiana de realidade psíquica, em que a deformação e a ilusão têm lugar privilegiado, pode-se dizer que não há ilusões na percepção.

Mas, de qualquer forma, nesse sentido o ser humano tem uma limitada possibilidade de percepção. Isto individualiza o seu estar no mundo e o limita no conhecimento aprendido que tem desse mesmo mundo. $O$ limite da percepção advém do fato de que é sempre como perspectivas que o homem retira do mundo suas percepções, quaisquer que sejam: os sons, o olhar, as temperaturas, os odores. Por essa razão, o outro, como parte fundante de todo conhecimento, deve sempre ser considerado como uma perspectiva. Um objeto não é percebido de uma só vez, isto é, por inteiro, pois somente percebemos uma de suas faces de cada vez. São diferentes perspectivas que direcionam as percepções, de não importa qual ordem - o mundo sempre é percebido por perfis. Tais perspectivas deformam por si mesmas o objeto, e são como uma condição da percepção. As deformações são produtos diferentes, oriundos dos pontos específicos de onde a experiência se dá.

A psicanálise procura propiciar, em certos casos, a experiência de uma certa qualidade da consciência que permite ao homem retirar do mundo os acontecimentos perceptivos que lhe outorgam alguma satisfação. Ao mesmo tempo, essa mesma qualidade deve permitir que o homem suporte não encontrar no mundo toda a sensorialidade um dia supostamente usufruída e nunca mais reencontrada.

Voltamos assim às questões anteriores, nascidas dos processos primário e secundário, e trabalhadas no início deste artigo, ou seja, todas as vicissitudes ligadas à questão da diferença. A percepção de si mesmo e a percepção do outro partem dessa vicissitude - a primeira é o limite a que a perspectiva obriga, em relação a ambas as partes. A segunda vicissitude diz respeito ao fato de que a percepção de si necessita, por definição, 
da percepção de um fora de si.Coelho Junior (2003), falando sobre a questão, ressalta sua defesa em relação ao conceito de intercorporeidade:

(...) justamente por entender que ela nos remete à valorização de um plano existencial que não pode ser tematizado a partir da primazia das filosofias do sujeito e das representações e exige um inevitável encontro com a radical alteridade do outro. (p. 208)

Essa afirmativa é uma expressão primorosa do pensamento de Merleau-Ponty (1945/1971). A passagem da filosofia para a psicanálise pode permitir o seguinte deslocamento: a comparação, a analogia, a projeção e a introjeção tornam-se processos indispensáveis para se chegar a uma alteridade. A noção de processo pode considerar a analogia, a introjeção e outras como formas gradativas e paulatinas de se conhecer o outro como alteridade.

Mas também se pode pensar esse processo em duas vias - tanto o ser conhece o outro em sua alteridade, quanto o outro, de seu lugar, fornece ao ser sua própria perspectiva de diferença. Assim, a alteridade do sujeito se situa, sobretudo, em sua passagem por um "outro" que o remete a si mesmo, em sua própria alteridade de si e do outro, por inferência. Essa forma de pensar ajuda a discernir entre a percepção e a consciência, sendo a primeira inerente ao organismo, e a segunda uma qualidade fundamental da aparelhagem psíquica freudiana.

Tal diferenciação, às vezes, não é tão simples assim - entretanto, é difícil pensar a percepção sem uma consciência qualquer. Mas, feita a distinção, é possível afirmar que a relação da percepção com a consciência é aquilo que possibilita esse ir-e-vir, em que a projeção, a introjeção, a comparação e a analogia são responsáveis tanto pelo outro em sua radical alteridade quanto pelo sujeito, também investido na mesma condição.

No artigo "O Inconsciente", Freud (1915b/1996) assim fala dos atributos do consciente:

A razão de ser de todas essas dificuldades reside na circunstância de que o atributo de ser consciente, única característica dos processos psíquicos que nos é diretamente apresentada, de alguma forma se presta a servir para a diferenciação de sistemas. (p. 197)

A consciência é a única passagem que permite conhecer a diferenciação de sistemas, e todo acesso que se tenha à alteridade, mesmo inferida como do outro, passa pela consciência. Tal premissa sustenta a afirmação de que sem a consciência não haveria nenhuma possibilidade 
de uma existência humana. Isso demonstra o estatuto fundamental da consciência. A consciência permite ainda diferenciar o que é inconsciente do que é pré-consciente. O pré-consciente é o mundo do recordável e das identificações conscientes, logo, o mundo do eu. Mas é a consciência que, por seu lado, em alguns momentos, pode tomar um certo contato com o sujeito do inconsciente e com o umbigo do sonho.

No artigo de Coelho Junior (s. d.) está dito que o mundo da percepção e da dependência é o corpo, e o mundo da consciência e da liberdade é uma corporalidade. Mas o que é uma corporalidade? A corporalidade é uma relação entre corpos, o que leva o autor a enfatizar que estamos, na nossa humanidade, misturados no mundo e aos outros numa confusão inexplicável, onde há aderência, envolvimento, mas não união dos contraditórios. Podemos dizer, dessa forma, que a relação entre o eu e o outro, como percepção e consciência, não é intermediada somente pela ação dos objetos sobre o "eu", nem somente pela ação do "eu" sobre as coisas - é a relação entre corpos que dá a cada corpo uma corporalidade possível.

Essa não-união dos contraditórios é a expressão da marca situada no portal do inconsciente chamado consciência - que, aqui, poderia ser referida como a "pele expressiva do mito individual", ou seja, o eu. Esse mito é também fruto da percepção e da consciência e tem um processo de individuação específico, denominado recalque, que poderia corresponder a alguns parcos espaços corpóreos que a experiência da realidade psíquica cria.

Aqui, aparece uma aproximação do conceito de corporalidade com o de realidade psíquica. O bebê, inicialmente, é um espaço que a biologia denomina carne. Mas a invenção do bebê (termo utilizado por Winnicott celebrando o nascimento do bebê freudiano) é um espaço de realidade psíquica, em todos os seus aspectos - perceptivos, conscientes e inconscientes. E, também, pela intervenção da mãe, como "outro" necessário.

O bebê, como corpo biológico, é antecipado como realidade psíquica ao ser inventado pelos pais, mas herda dessa invenção, que é também uma invenção da cultura nele, a possibilidade de se inventar na corporalidade. Tal corporalidade lhe permite transbordar para um mundo que será, doravante, como um dia lhe teria sido o seu corpo biológico originalmente. É nesse mundo, e não mais em si, que ele poderá reencontrar as sensações primitivas e importantes fornecidas por seus alicerces. Nele, também, serão reencontradas as seqüências de consciências iluminadas pela atenção.

Assim, a corporalidade é um trânsito entre carnes, seja de cada um (si mesmo) com o fora, inventado (mundo), seja entre os mundos dos "outros" e o "si mesmo de cada indivíduo". A "Carne em Trânsito" (chair) é descrita por Merleau-Ponty (1964/2000) em O Visível e o Invisível: 
A carne não é matéria nem é espírito, como também não é substância. Seria preciso, para designá-la, recorrer ao velho termo "elemento" no sentido em que era empregado para falar da água, do ar, da terra e do fogo, isto é, no sentido de uma coisa geral, meio caminho entre o indivíduo espaço-temporal e a idéia (p. 136)... Pertence, portanto, aos órgãos perceptivos e ao mundo. Mas onde colocar o limite do corpo e do mundo, já que o mundo é carne? (p. 138)

Carne é uma palavra forte, mesmo opaca.É evidente que MerleauPonty não nos fala da carne como biologia médica, embora aí tenha as suas raízes. Por que chamá-la de carne (chair) se uma outra palavra poderia ser inventada? Porque sua força é exatamente o deslocamento e a condensação que a palavra provoca, ou seja, ela mesma fornece a experiência de um esquecimento da biologia em favor do primado da consciência de uma outra realidade, que repouse na primeira e dela guarde elementos, mesmo que transformados.

Aqui chegamos a um momento importante deste trabalho. Acreditamos que esse paralelismo que propomos (filosofia e psicanálise) nos ajuda a pensar a clínica e a construir, nela, esses momentos que poderíamos denominar "processo de subjetivação do corpo".

A fenomenologia fornece uma base teórica que pode enriquecer a clínica psicanalítica dos casos acima citados, pois revela uma experiência do corpo como condição derradeira, mesmo que necessariamente obliterada. Entendemos, assim, que essa experiência é o fundamento da humanização de cada um, não passível de se integrar às premissas de uma filosofia tradicional. Luiz Damon Santos Moutinho (2006) marca essa preocupação da fenomenologia, ou seja, o rompimento com o cartesianismo que teria soterrado essa reflexão. Pois essas dificuldades encontradas por todos na experiência do corpo se tornam, também, um apelo clínico, encontrado no dia-a-dia do psicanalista. Não se trata de uma manifestação atual, muitas vezes considerada como uma característica da pós-modernidade. Acreditamos que a tradição esqueceu esses apelos. Eles estavam lá, no mundo e na clínica, e o conceito renovado de experiência que Merleau-Ponty nos fornece pode nos prometer uma melhor escuta dos mesmos.

Assim, Moutinho reconsidera esse mundo que, numa primeira abordagem, poderia ser pensado como um mundo de "coexistência pacífica" em que o eu desapareceria. Sendo assim, como poderia se dar uma pluralidade das consciências? Para o autor, Merleau-Ponty recoloca o problema da coexistência. Agora, trata-se da coexistência das liberdades e 
dos "eus", não mais dos sujeitos anônimos. Portanto, a filosofia da existência restaura essa extrema individualidade que é, também, uma premissa freudiana. Essa relação dos "eus" recoloca a questão dessa experiência enquanto experiência "de mim" e enquanto experiência do outro.

E porque se trata aqui de unidade, torna-se impossível determinar o que se deve ao eu natural e o que se deve ao eu pessoal, ao corpo e ao espírito. À natureza e à liberdade - ao contrário, essa estrutura se furta, como mostrávamos a propósito do percebido, a toda determinação, a toda univocidade:"o equívoco, diz Merleau Ponty, se torna essencial à existência humana".(Moutinho, 2006, p. 146)

Assim, esse equívoco, seja de cada eu, seja equívoco dos "eus", recoloca a importância de se pensar essa individualidade. Entretanto, a questão da construção dessa coexistência no equívoco continuaria a se impor.

Tentando levantar suas bases, utilizamos o mesmo texto de Coelho Junior (sem data). Dele se retira uma citação de Husserl (1934) em que o filósofo alemão retoma argumentos de sua "Quinta meditação", através justamente das noções de carne (chair) e de "expressão" (Ausdruck).

Meus modos de aparição me são dados de forma original, os do outro me são dados pela expressão enquanto presentificação (via empatia), portanto não de forma original. (...) o mesmo vale, inversamente, para eles, relativamente a seu mundo exterior, no qual minha carne (chair/Leib) funciona então enquanto expressão. No nosso ser-em-conjunto (Mit-sein), possuímos o mundo enquanto mundo de questões que nos são comuns (mundo exterior), no qual as carnes aparecem enquanto corpos que são capazes de funcionar como expressões. (p. 379)

Dessa forma, torna-se necessária a minha experiência da dor ou prazer para que eu possa apreender a dor ou o prazer "do outro"? Mas qual o processo que permitiria essa apreensão do "outro em dor"?

Essa questão também embaraça Freud: acha-se inserida, de uma maneira bastante particular, na sua obra. Trata-se de um engano encontrado no artigo "O Instinto e suas Vicissitudes (1915/1996). Essa dificuldade foi reformulada, em 1924, numa nota de rodapé (1915/1996); encontra-se na descrição feita por Freud da dinâmica entre o sadismo e o masoquismo (1915/1996). De início, Freud defende que o sadismo seria anterior ao masoquismo para, futuramente, recolocar o masoquismo, ou seja, a dor de cada um como absolutamente necessária nessa inferência e nesse gozo da dor "do outro". Essa mudança é importante na sua obra, pois não só marca uma reformulação na dinâmica dessa "aparição" como, também, aponta para novos movimentos teóricos que estariam se instalando. 
Qual seria o processo a permitir essa originalidade que, por sua vez, provocaria essa inferência do outro, por presentificação? A presentificação é o "corpo em si", agora não mais tomado como fonte de uma intersubjetividade, mas capacitado a construir uma subjetividade na "carne", construída pela sua "aparição aos outros corpos".

Assim, nessa citação, a palavra empatia é importante: se os dados de consciência são dados de forma original, solitária, os de um "outro" são dados dentro de uma categoria característica dessa transmissão - como empatia. Essa palavra tem sua origem em pathos, desordem, e explicita o caótico dessa via em duas direções em que a consciência se organiza. Trata-se da presentificação do outro na expressão da "carne".

Ter um "si mesmo" sem o outro é impossível, mas a alteridade do outro é desordem porque é diferença e equívoco. Para que a percepção e a consciência se façam expressão, seja no original de si mesmo ou na alteridade do outro, a desordem é condição. A empatia é uma forma de organização da desordem, um aglutinamento (algo muito perto das imantações).

Moutinho (2006), mais uma vez, nos ajuda a amparar nosso pensamento. Ele comenta a obra de Merleau-Ponty denominada "A Estrutura do Comportamento" (1990), e não só admite que o mundo das ciências clássicas começa a desmoronar e a exigir uma reforma de entendimentos, como introduz a importância da nova física e seus campos de força. Eles seriam como um campo de gravidade ou de imantações. Essa noção subverte as relações entre interior e exterior, organismo e ambiente, construções que são incapazes de esgotar seu objeto, ou seja, o organismo vivo, agora capacitado a estabelecer o ambiente não apenas como uma intersubjetividade mas como uma subjetividade expressiva.

O autor cita Merleau-Ponty, dando ênfase a esta assertiva:

Porque toda consciência de alguma coisa, desde que esta coisa...é identificável e reconhecível, (...) pressupõe, pela impressão vivida, a apreensão de um sentido que não está contido nela, não é dela uma parte real. A matéria do conhecimento torna-se uma noção limite posta pela consciência em sua reflexão sobre si mesma e não um componente do ato de conhecer. (Merleau-Ponty em "A Estrutura do Comportamento", citado por Moutinho, 2006, p. 84)

Freud, referindo-se a esse "não componente do ato de conhecer", comenta, na "História do Movimento Psicanalítico" (1914/1996), sua experiência com os seus mestres, dizendo: "Eles me transmitiram o que, rigorosamente falando, eles mesmos não possuíam" (p. 23), acreditando que seria este o mais importante efeito responsável pela invenção da psicanálise. A citação acima reforça um certo "conhecimento" enquanto uma 
aquisição da "carne" pois ele é, sobremaneira, a importante expressão empática de um campo de forças.

Essa mesma encruzilhada se encontra na compreensão do inconsciente freudiano. Ele poderia ser pensado como pertencente a cada um, como se cada ser possuísse essa faculdade de ter um inconsciente. Entretanto, o inconsciente é, tanto quanto o eu, uma construção do "entre", um campo formado entre dois sujeitos que buscariam um "conhecimento" qualquer do mesmo. Essa invenção, inicialmente, seria uma história do eu tomado como um arsenal de identificações, sem o qual o desejo inconsciente não teria um campo apto para se expressar.

Essa invenção se dá, nessa desordem, até que uma alteridade se instale, podendo ser paralela, em psicanálise, à característica de condensação que a transferência promove, tornando o analista atrativo na realidade do mundo e com o mesmo peso da atração do inconsciente, que teria promovido, por sua vez e anteriormente, algumas condições do recalcado.

Ora, essa desordem é difícil em algumas vicissitudes clínicas. Se para alguns clientes ela instala essa possibilidade de organização e transgressão, para outros ela é fonte de uma paralisia como defesa.

A "carne" é elemento, no sentido em que os antigos usavam a palavra, mais ou menos como a terra, a água, o ar e o fogo eram considerados. Para melhor estudar a clínica acima especificada, acreditamos importante pensar o texto sobre "A Aquisição e o Controle do Fogo" (Freud, 1931/ 1996).Tomando como referência o texto freudiano, seria o elemento fogo que mais se aproximaria da noção de "carne". O fogo não se encontra no mundo, como a "carne" também não. O relâmpago é fruto da natureza; o fogo, na fogueira, já é uma elaboração humana, um efeito do mundo que promove a invenção humana. Esses dois lugares, o do relâmpago e o do fogo, marcam o intervalo de desordem necessária para que o homem retire sua atenção do relâmpago para conceber a fogueira, que aquece e centraliza o grupo.É um "valor alfandegário" entre o mundo, como natureza, e"cada ser",como inventor e produtor de simbolizações.

\section{Reflexões finais}

O"eu" freudiano, cujo percurso foi descrito, é uma experiência constante. É produto de expressões, estímulo da "carne" como possibilidade que o homem teria de conjugar seu mundo interno com o mundo externo. Ao mesmo tempo, esse estímulo se faz nos dois sentidos e em dois tempos diferentes. Pode-se tanto pensar o "bebê como carne",estimulando o mundo na luta por sua inserção constante e progressiva nele, quanto o "mundo como carne", estimulando o bebê, inventando e reinventando-o como um mundo do bebê somente. 
Entretanto, os diversos momentos sobre a formação do eu, no texto freudiano, sobretudo a passagem do eu-prazer para o eu-realidade, levantam essa mesma questão. $O$ eu da realidade seria, no entender de muitos, uma concepção final do eu, estágio através do qual o eu chegaria à outra possibilidade de coexistir com a realidade do mundo. Mas o eu da realidade não é a expressão da realidade mesma. Ele é uma possibilidade política. É assim chamado porque possibilita o reencontro, no mundo, de objetos que possam ser fonte de satisfação. Sua "realidade" não é a expressão do seu conteúdo, mas a avaliação do seu sucesso.

Esse mesmo raciocínio pode orientar toda a leitura de "Três Ensaios sobre a Teoria da Sexualidade" (Freud, 1905). Trata-se do abandono da noção de estágio e sua retomada e re-entendimento em termos de perspectiva. Os estágios (oral, anal, fálico) não se excluem, desde que considerados como perspectivas diferentes, onde o eu se relança no objetivo de projetar sua dor, para nela, agora colocada fora, reencontrar uma realidade que é procura de um objeto de satisfação.

Freud, no "Projeto" (1895/1996), fala dessas perspectivas:

O enchimento dos neurônios nucleares no sistema dos neurônios impermeáveis terá como resultado uma propensão à descarga, uma urgência que se libera pela via motora. A experiência demonstra que, aqui, a primeira via a ser seguida é a que conduz à alteração interna (expressão das emoções, grito, inervação vascular). Mas como já explicamos, de início, nenhuma descarga desta espécie pode produzir resultado de alívio uma vez que o estímulo endógeno continua a ser recebido e se restabelece a tensão dos neurônios impermeáveis. Nesse caso a estimulação só é capaz de ser abolida por meio de uma intervenção que suspenda provisoriamente a descarga da quantidade no interior do corpo; uma intervenção desta ordem requer uma alteração no mundo externo (fornecimento de víveres, aproximação do objeto sexual) que, como ação específica, só pode ser conseguida através de determinadas maneiras. O organismo humano é, a princípio, incapaz de levar a cabo essa ação específica. Ela se efetua por meio da assistência alheia... essa via de descarga adquire, assim, a importantíssima função secundária da comunicação, e o desamparo dos seres humanos é a fonte primordial de todos os motivos morais. (p. 421)

Freud coloca o grito como uma expressão primitiva que tentaria uma alteração interna. Esse grito, no seu desamparo, se tornaria uma nova fonte de tensão. O organismo Bruto não consegue ações específicas para alterar a sua condição.Torna-se necessário "o outro",que se revela enquanto "carne." Ela é um trabalho paciente em que o "corpo Bruto" restabelece suas possibilidades, através das palavras, como um campo renovado.

Marilena Chauí (2002) define essa verticalidade para Merleau-Ponty: 
Verticalidade é o ser Bruto plantado diante de nós, exposto em suas raízes na simultaneidade de suas dimensões o sensível como famílias de estilos ou mundos de cada um dos sentidos, cada um dos quais irredutível aos outros e simultaneamente em comunicação com os outros pela equivalência das qualidades: a linguagem, invisível que não é negação do visível, mas seu avesso, experiência expressiva que não nasce contra o silêncio, mas se prepara nele com o trabalho paciente do desejo que pede expressão; as idéias sensíveis, "coesão sem conceito" ou estilo; e, enfim, as idealidades puras, afastamentos definidos ou delimitações abertas, que retomam o corpo glorioso das palavras num outro corpo, mais leve e transparente. (p. 113)

A autora enfatiza que "a verticalidade é uma desconstrução do espaço euclidiano e da pintura renascentista, deste espaço horizontal da representação contemplado em sobrevôo pelo sujeito do conhecimento" (2002, p. 112). A desconstrução dessa perspectiva corporal anterior é um esforço tanto para Freud como para Merleau-Ponty. Assim, a verticalidade é a perspectiva que nasceria do "ser Bruto", passando pela linguagem do silêncio ate "o corpo das palavras", como expressão de uma subjetividade que não mais seria um patrimônio de cada um mas um testemunho da "carne".

Esse "o que não é nós, ao mesmo tempo sendo" fala, também, da realidade psíquica da psicanálise que não se estende unicamente ao sujeito do desejo mas ao somatório de identificações que formam o eu, cujas raízes já se encontram além do mundo visível pelo seu estreito, embora traído, parentesco com a percepção.

Assim, a "carne do mundo", ou seja, a cultura e os corpos externos expressivos (biológicos ou não), em suas relações com o subjetivo de cada homem (carne do bebê e realidade psíquica), é o ponto onde se estabelece o valor "alfandegário" acima sugerido, ou seja, a dor do eu reencontrada no seu prazer do mundo. É esse percurso que permite ao eu reencontrar a ambivalência, anteriormente lançada no mundo, e assim, também, o objeto que lhe serve como catexia. $O$ "tornar consciente" é o percurso político de perlaboração, como produção de conhecimento de si e do mundo, que cada homem está sempre construindo na "carne" do mundo e vice-versa (mesmo que essa perlaboração seja atravessada pelo inconsciente). O mundo, como avesso do eu, fornece ao homem, dentro de seu processo de constituição e desenvolvimento, possibilidades de se reencontrar e, assim, preservar-se como biologia e como ser social. O pedaço de carne inventado como bebê seria o cerne da carne do mundo, de ora em diante disponível para sustentar esse mesmo bebê (biológico, sexual, social e inserido na linguagem).

Ora, a recolocação desse processo, aqui sugerido através dessa possibilidade de se pensar a "chair", como expressão na transferência, abre 
caminho para uma série de possibilidades clínicas e é um campo fértil para um clínico atento. A saída para a consciência do outro, como alteridade, só é possível através de uma subjetivação do corpo próprio. A expressão "tornar consciente" vincula duas idéias: inferir algo da experiência do outro e observar, para encontrar em si, uma possibilidade de internalizar essa experiência.

Mas tanto a inferência quanto a formação da imagem são expressões da corporalidade. Na corporalidade, a carne de um, lançada no mundo, se encontra na carne do outro, também lançada, para que re-efetue, na relação, uma troca expressiva e empática, denominada inconsciente, que, sem a base de um corpo subjetivado, não pode se dar como troca e expressão. E isto é importante, sobretudo como ponto de partida para uma pesquisa das vicissitudes e dificuldades no manejo da transferência, fartamente constatáveis nas neuroses narcísicas.

\section{The ego in Freud's work and the bodilyness.}

Abstract: This paper articulates the concept of ego in Freud's work to that of bodilyness in Merleau-Ponty's, allowing a theoretic course in which the body can be thought of in its intersubjective perspective. In bodilyness each person's "flesh",thrown into the world, meets itself in the other's flesh, equally thrown, so that it can rebound again in an expressive unconscious exchange in the relationship; but that, without the conscience of a body, made subjective, loses its possibilities as exchange and expression. In Freud, the chosen frame begins with the concepts of pleasure-ego and reality-ego, passing through the issue of the ideals where the possibility of thinking the relationship between ego and other is concretized. These concepts, through a parallel with the philosophical work, bring their support to psychoanalytic clinic.

Keywords: Ego. Perception. Conscience. Interpersonal relationship. Bodilyness.

\section{El yo en la obra de Freud y la corporalidad.}

Résumé: Le présent travail conjugue le concept du moi dans l'oeuvre de Freud et celui de corporéité chez Merleau Ponty, de façon à permettre un parcours théorique où le corps peut être entendu dans une perspective intersubjective. La corporalité, la "chair" de chacun, lancée au monde, se retrouve dans la "chair" de l'autre, également lancée au monde, pour réeffectuer, dans la relation, un échange expressif, inconscient, mais qui, sans la conscience d'un corps subjectivé, perd ses possibilités en tant qu'échange et expression. Le découpage chez Freud $s^{\prime}$ initie avec les concepts du moi plaisir et du moi réalité, en parcourant la question des idéaux où se concrétise la possibilité de penser les relations du moi avec l'autre. Ces concepts, mis en parallèle avec l'oeuvre philosophique, apportent un support à la clinique psychanalytique.

Mots-clés: Moi. Perception. Conscience. Relation interpersonnelle. Corporéité. 


\section{Le moi dans l'oeuvre de Freud et la corporalité.}

Resumen: Este artículo conjuga el concepto de yo en la obra de Freud con el concepto de corporeidad en la de Merleau-Ponty, abriendo un sendero teórico en que se puede pensar el cuerpo en su perspectiva intersubjetiva. En la corporalidad, la "carne" de cada uno, echada al mundo, se encuentra en la "carne" del otro, también echada, para que reefectúe, en la relación, un cambio expresivo inconsciente, el cual, sin embargo, sin la conciencia de un cuerpo subjetivado, pierde sus posibilidades de cambio y expresión. El tema, en Freud, se inicia con los conceptos de yo placer y yo de la realidad, recorriendo la cuestión de los ideales en que se concretiza la posibilidad de pensar las relaciones del yo con el otro. Dichos conceptos, en paralelo con la obra filosófica, ofrecen un soporte a la clínica psicoanalítica.

Palabras-clave: Ego. Percepción. Conciencia. Relación interpersonal. Corporeidad.

\section{Referências}

Anzieu, D. (1989). O eu-pele. São Paulo: Casa do Psicólogo.

Bergson, H. (1999). Matéria e memória. São Paulo: Martins Fontes. (Trabalho original publicado em 1939)

Chauí, M. (2002). Experiência do pensamento: ensaios sobre a obra de Merleau Ponty. São Paulo: Martins Fontes.

Coelho Junior, N. (2003). Da intersubjetividade à intercorporeidade: contribuições da filosofia fenomenológica ao estudo da alteridade. Psicologia USP, 14(1), 185-209.

Coelho Junior, N. (s.d.). Intersubjetividade e isolamento pessoal nas teorias fenomenológicas e psicanalíticas. Fotocópia.

Freud, S. (1996). Além do princípio de prazer. In Edição standard brasileira das obras psicológicas completas de Sigmund Freud (Vol. 18). Rio de Janeiro: Imago. (Trabalho original publicado em 1920)

Freud, S. (1996). A aquisição e o controle do fogo. In Edição standard brasileira das obras psicológicas completas de Sigmund Freud (Vol.22). Rio de Janeiro: Imago. (Trabalho original publicado em 1931)

Freud, S. (1996). O ego e o id. In Edição standard brasileira das obras psicológicas completas de Sigmund Freud (Vol. 19). Rio de Janeiro: Imago. (Trabalho original publicado em 1923)

Freud, S. (1996). Extratos dos documentos dirigidos a Fliess. In Edição standard brasileira das obras psicológicas completas de Sigmund Freud (Vol. 1). Rio de Janeiro:Imago. (Trabalho original publicado em 1887-1902)

Freud, S. (1996). Formulações sobre os dois princípios do funcionamento mental. In Edição standard brasileira das obras psicológicas completas de Sigmund Freud (Vol. 12). Rio de Janeiro:Imago. (Trabalho original publicado em 1911) 
Freud, S. (1996). Inibições, sintomas e ansiedade. In Edição standard brasileira das obras psicológicas completas de Sigmund Freud (Vol.20). Rio de Janeiro: Imago. (Trabalho original publicado em 1926)

Freud, S. (1996). Os instintos e suas vicissitudes. In Edição standard brasileira das obras psicológicas completas de Sigmund Freud (Vol. 14). Rio de Janeiro: Imago. (Trabalho original publicado em 1915a)

Freud, S. (1996). O inconsciente. In Edição standard brasileira das obras psicológicas completas de Sigmund Freud (Vol. 14). Rio de Janeiro: Imago. (TrabaIho original publicado em 1915b)

Freud, S. (1996). A interpretação dos sonhos. In Edição standard brasileira das obras psicológicas completas de Sigmund Freud (Vol. 4 e 5). Rio de Janeiro: Imago. (Trabalho original publicado em 1900)

Freud, S. (1996). As neuropsicoses de defesa. In Edição standard brasileira das obras psicológicas completas de Sigmund Freud (Vol.3). Rio de Janeiro:Imago. (Trabalho original publicado em 1894)

Freud, S. (1996). Uma nota sobre o "bloco mágico".In Edição standard brasileira das obras psicológicas completas de Sigmund Freud (Vol. 19). Rio de Janeiro: Imago. (Trabalho original publicado em 1925a)

Freud, S. (1996). A negativa. In Edição standard brasileira das obras psicológicas completas de Sigmund Freud (Vol. 19). Rio de Janeiro: Imago. (Trabalho original publicado em 1925b)

Freud, S. (1996). Neurose e psicose. In Edição standard brasileira das obras psicológicas completas de Sigmund Freud (Vol. 19). Rio de Janeiro: Imago. (Trabalho original publicado em 1924a)

Freud, S. (1996). Notas psicanalíticas sobre um relato autobiográfico de um caso de paranóia (dementia paranoides). In Edição standard brasileira das obras psicológicas completas de Sigmund Freud (Vol. 12). Rio de Janeiro: Imago. (Trabalho original publicado em 1910)

Freud, S. (1996). O problema econômico do masoquismo. In Edição standard brasileira das obras psicológicas completas de Sigmund Freud (Vol. 19). Rio de Janeiro: Imago. (Trabalho original publicado em 1924b)

Freud, S. (1996). Rascunho H. In Edição standard brasileira das obras psicológicas completas de Sigmund Freud (Vol. 1). Rio de Janeiro: Imago. (Trabalho original publicado em 1895a)

Freud, S. (1996). Projeto para uma psicologia científica. In S. Freud, Edição standard brasileira das obras psicológicas completas de Sigmund Freud (Vol. 1). Rio de Janeiro: Imago. (Trabalho original publicado em 1895b)

Freud, S. (1996). Psicologia de grupo e análise do ego. In Edição standard brasileira das obras psicológicas completas de Sigmund Freud (Vol. 18). Rio de Janeiro: Imago. (Trabalho original publicado em 1921) 
Freud, S. (1996). Rascunho N. In Edição standard brasileira das obras psicológicas completas de Sigmund Freud (Vol. 1). Rio de Janeiro: Imago. (Trabalho original publicado em 1897)

Freud, S. (1996). Sobre o narcisismo:uma introdução. In Edição standard brasileira das obras psicológicas completas de Sigmund Freud (Vol. 14). Rio de Janeiro: Imago. (Trabalho original publicado em 1914)

Freud, S. (1996).Totem e tabu. In Edição standard brasileira das obras psicológicas completas de Sigmund Freud (Vol. 13). Rio de Janeiro: Imago. (Trabalho original publicado em 1912-1913)

Freud, S. (1996). Os três ensaios sobre a teoria da sexualidade. In S. Freud, Edição standard brasileira das obras psicológicas completas de Sigmund Freud (Vol.7). Rio de Janeiro: Imago. (Trabalho original publicado em 1905)

Klein, M. (1991). Sobre a observação dos bebês. In Obras completa de Melanie Klein. Rio de Janeiro: Imago. (Trabalho original publicado em 1951)

Merleau-Ponty, M. (1971).Fenomenologia da percepção.São Paulo:Freitas Bastos. (Trabalho original publicado em 1945)

Merleau-Ponty, M. (2000). O visível e o invisível. São Paulo: Perspectiva. (TrabaIho original publicado em 1964)

Moutinho; L.D.S. (2006). Razão e experiência: ensaios sobre Merleau Ponty. São Paulo: Editora UNESP.

Winnicott, D. (2000). Objetos transicionais e fenômenos transicionais. In $D a$ pediatria à psicanálise. Obras escolhidas (Davy Bogomoletz, trad.). Rio de Janeiro: Imago. (Trabalho original publicado em 1951)

Recebido em:23/04/2007

Aceito em: 13/08/2007 